\title{
Concrete: Limit States and Sustainability
}

\author{
Kristýna Hrabová ${ }^{1}$, Břetislav Teplý ${ }^{2}$ and Tomáš Vymazal ${ }^{1}$ \\ Institute of Building Testing, Faculty of Civil Engineering, Brno University of Technology, Czech \\ Republic, Veveří 331/95, Brno 602 00, kristyna.hrabova@vutbr.cz, tomas.vymazal@vutbr.cz \\ ${ }^{2}$ Institute of Structural Mechanics, Faculty of Civil Engineering, Brno University of Technology, \\ Czech Republic, Veveří 331/95, Brno 602 00, teply.b@fce.vutbr.cz
}

\begin{abstract}
The structural design of concrete structures has to result in qualities ensuring ordinary structural safety and serviceability, together with durability. Recently, it has become necessary to pursue sustainability as well, and rather newly the issue of resilience has also appeared. It is now apparent that the effects of mechanical load, environmental load and even social coherence need to be reflected and included in the formulation of limit states. This is a complex matter involving the factors of time, service life, degradation effects, modelling, probability analyses, limit states, costs and other phenomena. It has not yet been completely understood, albeit several notions in this context are contained in different codes and regulations, e.g. EN 1990, EN 1992, ISO 13823:2008, ISO 16204:2012, fib MC2010 and fib MC2020 (currently under preparation by the fib committees). According to fib Model Code 2010, the design method most commonly used for concrete structures today is performance-based. Sustainable target value design can be briefly expressed as the comparison of sustainable capacity vs. sustainable impacts. This requires the formulation of a new class of limit states - apart from those of the engineering (or structural) type, also sustainability limit states now need to be specified. The presented contribution briefly mentions traditional and durability limit states, discussing their variants and context, and then concentrates specifically on the formulation of limit states for concrete sustainability at material level. It also presents some examples which apply a full probabilistic approach.
\end{abstract}

Keywords: Durability, Sustainability, Limit States, Concrete.

\section{Introduction}

When designing or assessing a RC structure in all situations and/or at all levels, use should be made of the limit state concept and performance models included in ISO 2394 (2015). Generally, possible structural responses are divided into two domains consisting of desirable or undesirable states; the boundary between these domains is called a limit state (LS). The traditional ultimate limit state (ULS) and serviceability limit state (SLS) were initially utilized in engineering practice (ISO 2394:1998) either as part of the semi-probabilistic format (partial factor) or in the fully probabilistic approach, which was mainly applied during research activities. Both material and structural levels were applied.

Limit state design is a common approach in civil engineering practice today. It is described in several international documents, e.g. EN 1992-1-1 (2004), ISO 16204 (2012) and fib MC2010 (2012). At the turn of the present century, the issue of durability and service life started to be considered important and thus relevant limit states appeared; however, up to now this theme has not yet been fully explored and definitively dealt with. Also, completely new types of engineering tasks have emerged recently, such as the maximising of sustainability 
and resilience, which may also need relevant definition and application in terms of limit states. A brief and effective overview of the LS context up to the current stage of progress with regard to sustainability LS can be found in Geiker et al. (2019).

Generally, structural assessment/analysis is governed by a LS probability condition which in its general form reads:

$$
P_{f}=P[A(t) \geq B(t)]<P_{d}
$$

$P_{d}$ is the design probability (target, limiting, required), $t$ is time, $S$ is the effect of the action being analysed and $R$ is the appropriate barrier (e.g. the resistance of the material or structure). Generally, both $S$ and $R$ are time-dependent and hence the probability of failure $P_{f}$ is time-dependent as well. At the point in time associated with the limit $P_{f}=P_{d}$, a design service life $t_{D}$ can be defined. The combined effect of both structural performance and ageing should be considered wherever relevant. Note that the index of reliability $\beta$ frequently stands in for the probability of failure $P_{f}$ in structural design practice (ISO 2394:2015). The present contribution briefly reviews the development of LS issues and concentrates on the formulation of material sustainability limit states, showing some examples.

\section{Traditional LS}

The traditional ultimate limit state (ULS) and serviceability limit state (SLS) were presented in the nineties in standards - see ISO 2394 (2015)

\section{The ULS concerns th \\ for material deterioration \\ the component or struct \\ The SLS concerns}

appearance of construction work. For material degradation,

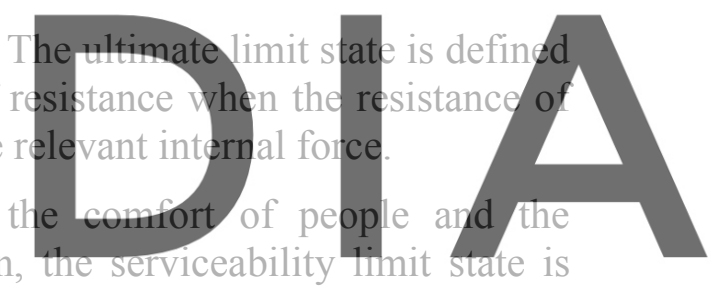

defined by:

Register for free at https//www.șcipedia.com to download the version without the watermark Local damage (including cracking) or changes in appearance which affect the function or appearance of structural or non-structural components.

- Relative displacements which affect the function or appearance of structural or nonstructural components.

An allowable value (target, design) $P_{d}$ for the probability of failure was given in EN 1990, Annex C (EN 1990:2002/A1:2005/AC:2010), differentiating them according to LS type, three reliability classes and three consequence classes. A distinction must be made between the design of new structures and the assessment of existing structures. Note that at the beginning of limit state development the level of reliability in the context of durability was left to the client's decision, together with the definition of the target service life.

\section{The Durability Concept}

According to Tutti (1982), the durability of reinforced concrete components or structures was later included in the LS concept mainly in connection with the consideration of reinforcement corrosion - (i) an initiation period (reinforcement depassivation leading to corrosion initiation, usually due to carbonation or chloride ingress) and (ii) a propagation period (the 
development of reinforcement corrosion with a decrease in the effective reinforcement area, crack formation and spalling). There are numerous research works dealing with the durability of concrete structures, of which only a few of the earliest of them shall be mentioned here, e.g. Mehta (1997), Rostam and Schiessl (1994), Keršner et al. (1996) and Gehlen (2000). The durability of concrete structures is influenced by degradation effects and exposure conditions, and using appropriate LS the service life L can be assessed as well. This can be performed with a suitable model analysis via the use of effective software tools, e.g. Matesová et al. (2008), Life 365 (effect of chloride ingress) or Novák et al. (2014), Teplý et al. (2018) (FReET-D, incorporating a number of different numerical degradation models in a probabilistic format, producing statistical, sensitivity and probability analyses). Broadly accepted models (carbonation, and chloride effect) were included in the Model Code for Service Life Design (2008) and later in fib Model Code 2010 (2012).

The time passing before the initiation of rebar corrosion is usually considered the most conservative limiting state. It is known as the durability limit state (DLS) or initial limit state - see ISO 13823 (2008). Note that this category of LS is referred to the SLS in ISO 2394 (2015). For such a probability condition the basic form (1) can be reformulated as follows:

$$
P_{f}\left(t_{D}\right)=P\left\{a-x_{c}\left(t_{D}\right) \leq 0\right\} \leq P_{d}
$$

The thickness of concrete cover $a, \mathrm{x}_{\mathrm{c}}$ is the depth of the carbonated zone, $\mathrm{t}_{\mathrm{D}}$ is the design (target) service life and $\mathrm{P}_{\mathrm{d}}$ is the design (target) probability of "failure".

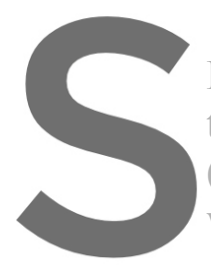

Evidently, during

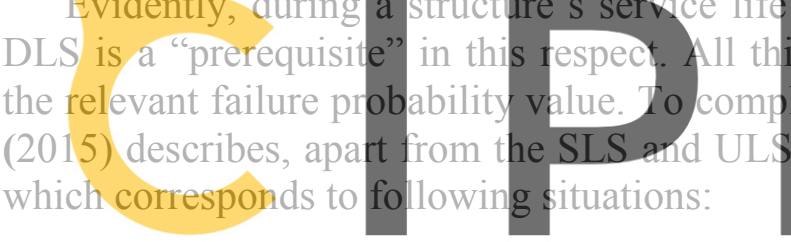

An approximation to the real LS that is either not well-defined or is difficult to calculate

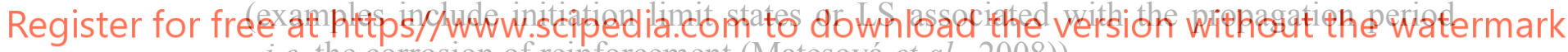
- i.e. the corrosion of reinforcement (Matesová et al., 2008)).

- Local damage (including cracking).

- Additional LS thresholds in the case of a continuously increasing loss of function.

The CLS has not yet been fully understood and utilized in practice; this kind of LS is expected to be presented and explained in more detail by the upcoming fib Model Code 2020. Moreover, when dealing with durability tasks this LS is often affected by a particular combination of actions (mechanical, environmental); see e.g. Vořechovská et al. (2008). Also, the eventual reversibility or irreversibility of the LS has to be taken into account.

\section{The Limit State Concept from the Perspective of Sustainability}

According to the fib Model Code 2010 (2012), the most commonly used method of designing concrete structures today is performance-based design. Sustainable target value design can be briefly expressed as the comparison of sustainable capacity vs. sustainable impacts. This requires a new class of limit state - apart from those of the engineering (or structural) type, sustainability limit states have to be specified as well. This was mentioned in the fib Model 
Code 2010 (2012), and also in Geiker et al. (2019), which states that by means of Eq. (1) the environmental performance of a concrete structure shall be verified by confirming that the retained performance or barrier $(\mathrm{R})$, defined by using appropriate indexes with regard to the environment, is larger (or smaller) than the set value or effect of the action (S) of the relevant performance requirement (Section 7.10) (fib Model Code 2010; 2012). Social performance is described in a similar way in this section. Note that in this respect, safety, serviceability and durability are also social aspects (Hájek, 2018), i.e. elements of social responsibility, and therefore SLS, ULS and $L$ also fall into this category - usually being understood and utilized as basic safety and serviceability criteria as well. Details concerning this class of limit equations and their practical utilization have not yet been specified in the fib Model Code 2010 (2012) or anywhere else to the best knowledge of the authors; an overview of the equations and a short literature review can be found in Hrabová et al. (2019).

The new fib Model Code 2020, which is currently under development, will include an implementation of the sustainability approach (Matthews, 2017): "MC2020 will take sustainability as a fundamental requirement, based upon a holistic treatment of societal needs and impacts, lifecycle costs, and environmental impacts." The limit state approach is not yet commonly used for sustainability analysis and the relevant limit states are not being employed in practice at the present time. A recent paper discusses this without formulating relevant limit state equations. A new design limit state approach is needed, and it has to be based on the probabilistic approach combined with the life cycle approach. It is a highly complex matter, as besides the existing construction limit states, new sustainability LS (environmental and social) need to be addressed together with service life and/or
not yet been identified. However, somg recent works deserve
are briefly mentioned below.
Fantilli et al. (2019) presented a procedurd for RC beam
the beam", which introcluces the specific limit state of sustai

ULS and SLS). It is based on a function relating the mass of $\mathrm{CO}_{2}$ emitted by the production of

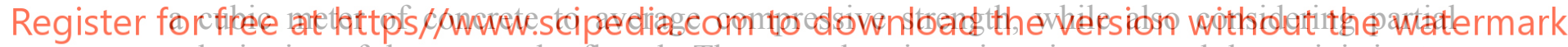
substitution of the cement by fly ash. The procedure is an iterative one and deterministic, i.e. it does not result in a relevant probability level. The durability issue is not considered, so the LS presented in Fantilli et al. (2019) is not a true sustainability limit state.

Geiker et al. (2019): in their work a sustainability LS is advocated using a comparison of two potential design scenarios. Considering each scenario's full design service life, a cumulative emissions envelope can be computed for both scenarios and the actual reduction target (global warming potential emission reduction) is assessed together with the probability of failing to meet a sustainability-focused goal. Reliable and valid models for the assessment of degradation (e.g. for corroding structures) are needed to check engineering LS; this also leads to an iterative process. Moreover, there are not yet any approved acceptable failure probability values for a sustainability LS.

Authors of the present contribution have developed a sustainability LS formulation at material level using the sustainability potential indicator $k_{S B}$, Eq. (3). This combined indicator was recently presented in, e.g. Hrabová et al. (2019), Teplý et al. (2018) and Konečný et al. (in revision). Indicator $k_{S B}$ is a normalized form of the Building Material Sustainability Potential (BMSP) defined previously by Müller (2013). In order to transform the BMSP into a normalized form, the quantities $L$ (service life), $R$ (performance) and $E$ (eco-cost) are divided 
by the arbitrary reference values $L_{r e f}, R_{r e f}$ and $E_{r e f}$, thus leading to a dimensionless quantity (3) whose value approximates 1.0. The greater the value of $k_{S B}$, the higher the sustainability level within the group of studied mixes for concrete production; the ranking of $k_{S B}$ values is the resulting information. It should be noted that the presented method is supposed to enable the comparison of concrete mixture sustainability levels within a group of analysed mixtures under a given degradation effect.

$$
k_{S B}=\frac{\frac{R}{R_{r e f}} \cdot \frac{L}{L_{r e f}}}{\frac{E}{E_{r e f}}}
$$

Eq. (3) can be further enhanced by considering the costs, C, of concrete (material and production) leading to a modified indicator. More details can be found in, e.g. Konečný et al. (in revision). Additionally, for any individual concrete composition using $k_{S B}$ as an action and the limiting value indicator $k_{S B \text {, lim }}$ as a barrier, the general limit state condition (1) may be rewritten into the sustainability LS form.

$$
P_{S B}=\left[\left(k_{S B}-k_{S B, l i m}\right) \leq 0\right] \geq P_{d . S B}
$$

This equation enables the evaluation of the probability $P_{S B}$, with which a certain limit value $k_{S B, \text { lim }}$ can be exceeded for the concrete mixture in question. However, this value has not yet been discussed and no experience or recommendations are known in this respect. Note that $k_{S B}$, lim depends on three involved factors, $R, L$ and $E$, which makes its determination complex. A less complicated option can be formulated utilizing the individual limit values $R_{\text {lim }}, L_{l i m}$ and
Elim of quantities $R, L$ and $E$, respectively, or in other words to determine the $k_{s B, l i m}$ value as
follows:
\[ k_{S B, l i m}=\frac{\frac{R_{l i m}}{R_{r e f}} \cdot \frac{L_{l i m}}{L_{r e f}}}{\frac{E_{l i m}}{E_{r e f}}} \]

Register for free at https//www. scipedia.com to download the version without the watermark of dominance. In such a case a more fitting variant of Eq. (5) can be arranged using the weighting coefficients $w_{R}, w_{L}$ and $w_{E}$ :

$$
\boldsymbol{k}_{S B, \text { lim }}=\frac{w_{R} \frac{R_{\text {lim }}}{R_{\text {ref }}} \cdot w_{L} \frac{L_{l i m}}{L_{\text {ref }}}}{w_{E} \frac{E_{\text {lim }}}{E_{\text {ref }}}}
$$

Alternatively only one of the quantities $R_{\text {lim }}, L_{\text {lim }}$, or $E_{\text {lim }}$ can be employed individually in (5) when $k_{S B \text {, lim }}$ is computed (case dependent).

A major obstacle for the effective utilization of the limit state condition (4) is the choice of a suitable value for target reliability $P_{d, S B}$, which is not yet available in any recommendation or standard. The following notes can provide a degree of help when deciding about the $P_{d, S B}$ value:

- in situations when material parameter $R$ is dominant (e.g. considering requirements for the robustness of the structure or the resilience of its functionality), a $P_{d, S B}$ reliability similar to a relevant one from the ULS group, i.e. $3.7 \leq \beta \leq 4.4$ according to ISO 2394 (2015), may be acceptable; 
- in cases where $L$ is dominant (if durability is at the centre of interest) then a $P_{d, S B}$ value in the range of $0.8<\beta_{d} \leq 1.6$ similar to the SLS or DLS could be relevant;

- if the environmental issue dominates, e.g. via the eco-costs $E$ (expenditures on measures to be taken so as to reduce environmental impacts to a sustainable level), then it is not straightforward to decide on a relevant $P_{d, S B}$. Environmental impact targets and/or greenhouse gas reductions must be considered, and also associated human health consequences need to be thought about. In such cases, the involvement of policymakers at a local or regional level is needed.

Unfortunately, there are no historical bases available for considering an acceptable failure probability for sustainability limit states. A brief discussion of this problem can be found in Geiker et al. (2019).

\section{Numerical Demonstration of the Presented Approach}

A simple example of the sustainability limit state assessment of concrete composition is presented below. The sample consists of $290 \mathrm{~kg} / \mathrm{m}^{3}$ CEM I $42.5 \mathrm{R}, 812 \mathrm{~kg} / \mathrm{m}^{3} 0-4 \mathrm{~mm}$ aggregate, $910 \mathrm{~kg} / \mathrm{m}^{3} 8-16 \mathrm{~mm}$ aggregate, $194 \mathrm{~kg} / \mathrm{m}^{3}$ fly ash, and $182 \mathrm{~kg} / \mathrm{m}^{3}$ water. The concrete in question is supposed to suffer from carbonation, so the service life $L$ is calculated according to the initiation period stage of reinforcement corrosion caused by concrete carbonation using an analytical model. The FReET-D tool with model Carb4b are used

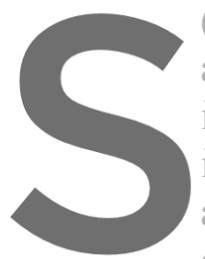
(Papadakis and Tsinnas, 2002). The basic atmospheric $\mathrm{CO}_{2}$ conce in EN 206-1, 2013).

in this example. It was at the Faculty of Civil concrete mixture elentont has aunit price obta
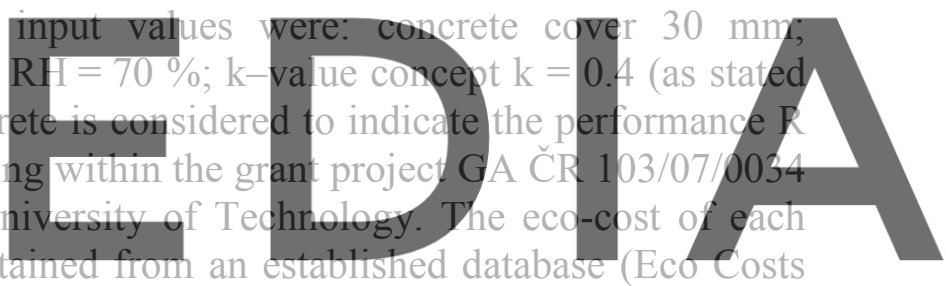

Data, 2019). Reference values (chosen arbitrarily) used: $\mathrm{R}_{\text {lim }}=71.9 \mathrm{MPa}$, Llim $=125$ years and Register for frees atehthtps//www.scipedia.com to download the version without the watermark

Table 1. Concrete properties.

\begin{tabular}{lccc}
\hline Property & Pdf & Mean & COV \\
\hline 60-day cube strength $[\mathrm{MPa}]$ & Normal & 47.2 & 0.06 \\
\hline Service life [years] & Normal & 73 & 0.16 \\
\hline Eco-costs $\left[€ / \mathrm{m}^{3}\right]$ & Rectangular & 54.3 & 0.20 \\
\hline
\end{tabular}

Limit values were chosen for the purpose of this illustrative example via the authors' engineering judgement in order to represent the trend of the probability $P_{S B}$ due to limit values $\mathrm{R}_{\text {lim }}$ while keeping $\mathrm{L}_{\text {lim }}$ and $\mathrm{E}_{\text {lim }}$ unchanged. Therefore, three cases $(\mathrm{A}, \mathrm{B}$ and $\mathrm{C}$ ) were analysed: A: $\mathrm{R}_{l i m}=95 \% \mathrm{R}_{\text {ref; }} \mathrm{L}_{\text {lim }}=0.66 \mathrm{~L}_{\text {ref }}, \mathrm{E}_{\text {lim }}=1.33 \mathrm{E}_{\text {ref; }} \mathrm{B}: \mathrm{R}_{\text {lim }}=90 \% \mathrm{R}_{\text {ref; }} \mathrm{L}_{\text {lim }}=0.66$ $\mathrm{L}_{r e f} ; \mathrm{E}_{l i m}=1.33 \mathrm{E}_{r e f}, \mathrm{C}: \mathrm{R}_{l i m}=85 \% \mathrm{R}_{r e f}, \mathrm{~L}_{l i m}=0.66 \mathrm{~L}_{r e f} ; \mathrm{E}_{l i m}=1.33 \mathrm{E}_{r e f}$. 
Kristýna Hrabová, Břetislav Teplý and TomášVymazal

Table 2. Conclusions.

\begin{tabular}{lccc}
\hline & $\mathrm{A}$ & $\mathrm{B}$ & $\mathrm{C}$ \\
\hline $\mathrm{k}_{S B}$ & 1.04 & 1.04 & 1.04 \\
\hline $\mathrm{k}_{S B, \text { lim }}$ & 0.49 & 0.47 & 0.44 \\
\hline $\mathrm{P}_{S B}$ & 0.04 & 0.03 & 0.03 \\
\hline$\beta$ & 1.74 & 1.84 & 1.95 \\
\hline
\end{tabular}

The values obtained for $k_{S B}$ and $P_{S B}$ were analysed using a specialized version of FReET software and applying Eq. (3) and (4). As mentioned above, relevant values for the target reliability $P_{d, S B}$ are not available in any recommendation at present. The resulting probability values (and the associated index of reliability $\beta$ ) in the studied ad-hoc case (Table 2) fall into the range "between" usual ULS and SLS values.

\section{Concluding Remarks}

The paper discusses limit state variants in the context of concrete structures, reviews the current position with regard to traditional Ultimate Limit States and Serviceability Limit States, and mentions Durability LS (initiation and propagation stages) as well as Condition Limit States. It then concentrates on the deseription and formulion of lim states for material sustainability, of LS. A general definition officially.

This contribution presents a novel form sustainability potential indicator. This indicato
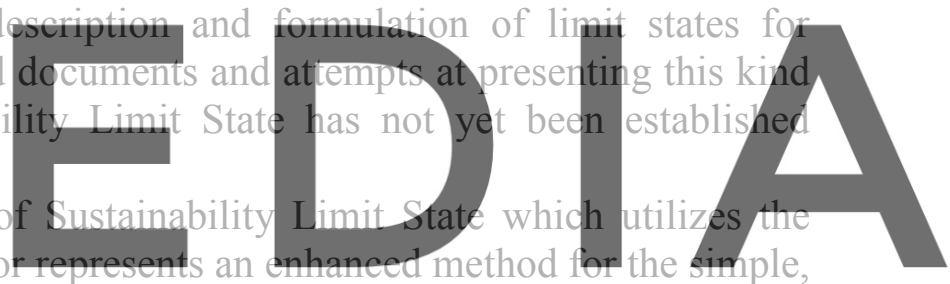

yet complete sustainability assessment of concrete mixtures, which involves concrete

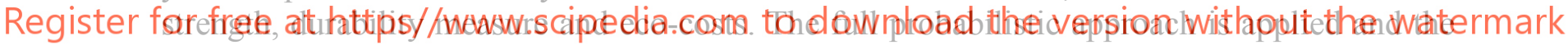
method illustrated on an ad-hoc case - concrete suffering from carbonation. The resulting probability values and associated values of index of reliability $\beta$ for different limit values are shown. The study provides engineers and researchers with an emerging tool for effective decision-making concerning concrete mixes that gives consideration to sustainability.

\section{Acknowledgements}

This work was supported by Czech Science Foundation project No. 19-22708S.

\section{ORCID}

Kristyna Hrabova http://orcid.org/0000-0003-2078-1898

Bretislav Teply: http://orcid.org/0000-0001-9067-9122

Tomas Vymazal: http://orcid.org/0000-0002-3633-047X

\section{References}

Eco Costs Data, Design-4-Sustainability: Inspiration and knowledge by designers for designers [online] Available in: http://www.design-4-sustainability.com/ecocosts.

EN 1990:2002/A1:2005/AC:2010 (1990) Eurocode - Basis of structural design.

EN 1992-1-1 (2004). (English): Eurocode 2: Design of concrete structures - Part 1-1: General rules and rules for buildings. 
EN 206 (2013). Concrete Specification, performance, production and conformity, Brussels: European Committee for Standardization - CEN.

Fantilli A.P., Tondolo P., Chiaia B. and Habert G. (2019). Designing Reinforced Concrete Beams Containing Supplementary Cementitious Materials. Materials 2019,1248; https://doi.org/10.3390/ma12081248.

fib bulletin 34 (2006). Model Code for Service Life Design, International Federation for Structural Concrete (fib), Lausanne Switzerland.

fib bulletin No. 65 and 66 fib Model Code 2010 (2012). International Federation for Structural Concrete (fib), Lausanne Switzerland.

Gehlen, Ch. (2000). Probabilistishe Lebensdauerbemessung von Stahlbeton bauwerken, Deutsher Ausschuss fuer Stahlbeton, Heft 510, Berlin.

Geiker M.R., Michel A., Stang H., Vikan and Lepech MD (2019). Design and maintenance of concrete structures requires both engineering and sustainability limit states. Life-Cycle Analysis and Assessment in Civil Engineering: Towards an Integrated Vision, London.

Geiker M.R., Michel A., Stang H. and Lepech M.D. (2019). Limit states for sustainable reinforced concrete structures. Cement and Concrete Research 122, 189-195.

Hájek P. (2018). Contribution of concrete structures to sustainability-challenge for the future. IOP Conference Series: Materials Science and Engineering, Volume 442.

Hrabová K., Teplý B. and Hájek P. (2019). Concrete, sustainability and limit states. IOP Conference Series: Earth and Environmental Science, vol. 290, no. 1, p. 1-9. ISSN: 1755-1315.

Chromá, M., Rovnaník, P. and Teplý, B. (2007). Carbonation modelling and reliability analysis of $R C$ structures made from blended cements, Proc. of International RILEM Workshop on Performance Based Evaluation and Indicators for Concrete Durability, 19-21 March 2006, Madrid, Spain, 319-325.

ISO/TC 98/SC 2 (2008) ISO 13823: General Principles on the Design of Structures for Durability.

ISO/TC 71/SC 3 (2012) ISO 16204:Durabilitu - Service life design of concrete structures.

ISO/TC 98/SC 2 (2015) ISO 2394

Keršner Z., Teplý B. and concrete. 7 th Internationa

Stockholm, Sweden,

Konečný P., Ghosh P. assessment of concretemint.
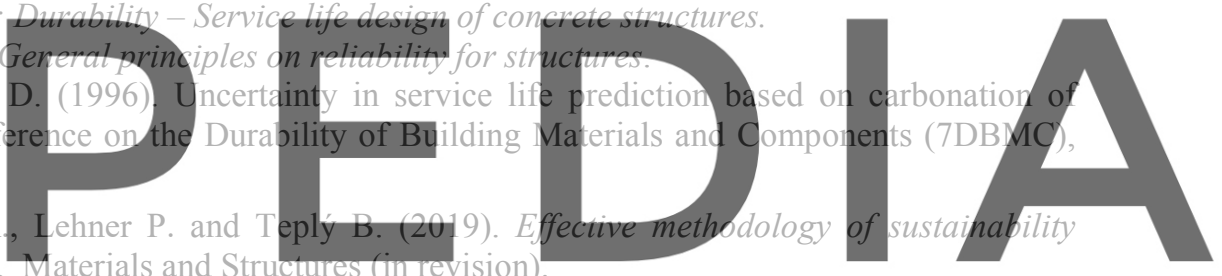

Matesová D., Chromá M. and Teplý B. (2008). Durability Limit States of Concrete Structures: Probabilistic

Register for

Matthews S. (2017). fib Model Code 2020 - A new development in structural codes, Structural Concrete Journal of the fib, Volume 18, Issue 5, 651-652.

Müller H.S. (2013). Sustainable structural concrete - from today's approach to future challenge. Structural Concrete 14 (4), 299-300.

Novák, D, Vořechovský, M and Teplý, B (2014). FReET - Software for the statistical and reliability analysis of engineering problems and FReET-D: Degradation Module, Advances in Engineering Software, 179-192.

Papadakis V.G. and Tsimas S. (2002) Supplementary cementing materials in concrete, Part I: Efficiency and design, Cement and Concrete Research 32 (10), 1525-1532.

Rostam S. and Schiessl P. (1994). Service Life Design in Practice - Today and Tomorrow, Proceedings, International Symposium "Concrete Across Borders", Odense, Denmark.

Teplý, B., Vořechovská, D. and Chromá, M. (2018). Probabilistic based models for material degradation processes. Chapter in fib Bulletin No. 86, The International Federation of Structural Concrete.

Teplý B, Rovnaníková P. and Vymazal T. (2018). Sustainability Quantification of Concrete Structures. Chapter in Advances in Environmental Research, Vol 63, NOVA Science Publishers, NY, USA, 231-248.

Tuutti, K. (1982). Corrosion of steel in concrete, Swedish Cement and Concrete Research Inst., 17-21.

Vořechovská D., Šomodíková M., Podroužek J., Lehký D. and Teplý B. (2008). Concrete structures under combined mechanical and environmental actions: Modelling of durability and reliability. Computers and Concrete, Vol. 20, No. 1, 99-106. 